\title{
Immunohistochemical diagnosis of Caprine alphaherpesvirus 1 (CpHV-1) in Mexico
}

\author{
Samantha P. Llanos-Salinas ${ }^{a}$, Laura Cobos-Marín ${ }^{b}$, Eugenia Candanosa-Aranda ${ }^{a^{*}}$
}

\begin{abstract}
The aim of this study was to identify the presence of Caprine alphaherpesvirus 1 (CpHV-1) in goat organs with suggestive injuries caused by the virus. A descriptive and retrospective study was performed, selecting necropsy cases suggestive of CpHV-1infection during a period of five years. Forty eight suspected cases were obtained, to which the immunohistochemistry technique with a CpHV-1 monoclonal antibody, was applied. We observed positivity in 24 goatling cases under 15 days $(50 \%)$ and in 4 cases of adult animals (8.3\%). The presence of CpHV-1 in goats from the Mexican plateau is confirmed.

Key words: Caprine alphaherpesvirus, immunohistochemistry.
\end{abstract}

\section{INTRODUCTION}

During the year of 1972 in the Santa Cruz County, California, four goatlings aged one week old died after presenting a generalised infection, dyspnea, appetite loss and abdominal pain in an Alpine-French goat upbringing. In the samples sent to the laboratory, several intranuclear inclusion bodies, similar to herpes virus were identified (Saito et al 1974)). Some years later, CpHV-1 was identified in goatlings from the Bregaglia Valley in Switzerland (Mettler et al 1979).

Existing data suggest that Caprine alphaherpesvirus 1 is global, with variable prevalence. The disease has been identified in Australia, Canada, USA, and New Zealand (Grewal and Wells 1986, Horner et al 1982, Piper et al 2008, Tarigan et al 1987) and seems prevalent in Europe, especially in the Mediterranean basin. In countries where goats are economically important as Spain, Italy, Greece and France, stronger prevalence was observed (Keuser et al 2004, Koptopoulos et al 1988, Sauvet et al 2016, Thiry et al 2008, González et al 2017). In Mexico, a report published in the year of 2011 suggested the presence of Caprine alphaherpesvirus 1 in a goat flock located in Tequisquiapan, Queretaro, when several lesions such as vulvovaginitis and pustular ulcerative balanoposthitis, were observed. In this study, eosinophilic intranuclear inclusion bodies were found in different organs of two adult animals and stillbirth. In order to identify the virus, electronic microscopy and cell culture were performed, which generated the expected cytopathic effect (Candanosa et al 2011).

Accepted: 22.06.2018.

${ }^{a}$ Laboratory of Pathology, Highlands Teaching and Research Farm, Faculty of Veterinary Medicine, National Autonomous University of Mexico (UNAM), Tequisquiapan, México.

${ }^{b}$ Microbiology and Inmunology Department, Faculty of Veterinary Medicine, National Autonomous University

*Corresponding author: E Candanosa-Aranda; Carretera TequisquiapanEzequiel Montes Km 8.5 Tequisquiapan, Querétaro, México, CP 76750; ieca@unam.mx
Due to the evidence of suggestive CpHV-1 lesions in Mexican goat herds, it is necessary to identify the virus and to inform the caprine producers, so they can consider this agent as a possible cause of economic losses in the herd, reproductive problems in adults, abortions and mortality in neonates.

The aim of this study was to determine the presence of CpHV-1 in goat organs which had suggestive injuries caused by the virus, through an immunohistochemical technique using a monoclonal antibody against glycoprotein $\mathrm{C}$ of $\mathrm{CpHV}-1$.

\section{MATERIAL AND METHODS}

This work corresponds to a descriptive and retrospective study. Pathological cases with lesions suggestive to CpHV1, belonging to the acquis of the Highlands Teaching and Research Farm, Faculty of Veterinary Medicine, National Autonomous University of Mexico (UNAM), were used. For the immunohistochemical study, autopsy goat reports with lesions suggestive to $\mathrm{CpHV}-1$ infection from the Mexican plateau during the period of five years, were reviewed.

\section{SAMPLES}

Paraffin blocks containing organ sections, previously fixed with $4 \%$ formalin buffered and processed using the paraffin embedding routine method, were obtained. Cuts measuring $3 \mu \mathrm{m}$ thick were made and placed in electro charged slides.

\section{IMMUNOHISTOCHEMICAL ANALYSIS}

To achieve identification of the viral antigen, the immunochemistry (IHQ) streptavidin-biotin-peroxidase technique was used. A monoclonal primary antibody against glycoprotein $\mathrm{C}$ of $\mathrm{CpHV}-1$ was used, which was donated by Dr. Etienne Thiry from the Infectious and Parasitic Disease Department of the Virology and Immunology Laboratory, Faculty of Veterinary Medicine, University 
of Liege in Belgium (Keuser et al 2004), because a commercial antibody is unavailable in the market.

As positive control, liver sections of a Syrian golden hamster inoculated with $\mathrm{CpHV}-1$, previously isolated in cell culture and identified by indirect immunofluorescence with the monoclonal antibody, were used, while negative controls were: a liver section of a clinically healthy Syrian golden hamster and a liver section of a healthy bovine (figure 1). In both cases, tissue samples were fixed in $4 \%$ formalin buffered and embedded in paraffin, then $3 \mu \mathrm{m}$ thick cuts were made and placed in electro charged slides. All histological sections were deparaffinised in an oven at $60{ }^{\circ} \mathrm{C}$ for $1 \mathrm{~h}$. Subsequently, the tissues were immediately immersed in xylol, and 2 washes of 5 min each were performed. For tissue rehydration, slides were immersed in ethyl alcohol at different concentrations: $100 \%, 96 \%$, $80 \%, 70 \%$ and 50\%; performing 3 min washes for each alcohol concentration, and finally they were immersed in distilled water during $3 \mathrm{~min}$ at room temperature.

Antigenic recovery was made through an antigen recovery pot at a temperature of $120^{\circ} \mathrm{C}$ for $10 \mathrm{~min}$, using a sodium citrate buffer with a $\mathrm{pH} 6.0$ (20X immuno/DNA Retriever with citrate, Bio SB Inc).

In order to inhibit the endogenous peroxidase activity, a peroxidase commercial blocker (Mouse/rabbit Immunodetector peroxidasa block, Bio SB Inc) was used, applying 4 drops on the tissue. This blocker was allowed to act for $5 \mathrm{~min}$ in a humid chamber at room temperature.

The primary antibody was employed at a 1:100 dilution using an antibody diluent (Mouse/rabbit Immunodetector biotin link, Bio SB Inc). For each slide, $100 \mu \mathrm{L}$ were applied and incubated for $60 \mathrm{~min}$ in a humid chamber at room temperature.

A commercial secondary antibody marked with biotin (anti-mouse/rabbit biotinylated Immunodetector, Bio SB Inc), was used; applying 4 drops on the tissue, and let it incubate for $15 \mathrm{~min}$ in a humid chamber at room temperature. In order to remove the antibody excess, distilled water washes were performed.
Subsequently, 4 drops of HRP immunosensor (Mouse/ rabbit Inmunodetector HRP label, Bio SB Inc) were applied and incubated for $15 \mathrm{~min}$ in a humid chamber at room temperature. In order to remove the excess, distilled water washes were performed.

A $100 \mu \mathrm{L}$ of diaminobenzidine (Immunodetector DAB Chromogen, Bio SB Inc) was applied and left on for 5 min as development time. Then, a soft washing with distilled water was performed on each slide in order to stop the reaction. Tissues were contrasted with Meyer's hematoxylin, immersing them in the staining during $2 \mathrm{~min}$, and then they were washed with tap water. Subsequently, the slides were placed in distilled water for $3 \mathrm{~min}$. Tissues were dehydrated through 3 min washes using different alcohol concentrations: $50 \%, 70 \%, 80 \%, 96 \%$ and $100 \%$; then, they were dried at room temperature. Finally, the slides were covered with a coverslip in order to seal them with synthetic resin.

A positive reaction was determined by observing an ocher color in the cytoplasm and/or cell nucleus, which established the presence of herpes viral particles.

The positivity degree was described as: mild positivity (ocher color), moderate positivity (ocher), and strongly positive (dark ocher).

\section{RESULTS AND DISCUSSION}

The main goal of this work was to identify the presence of CpHV-1 in goat organs with suggestive injuries caused by the virus. Forty eight cases were obtained; of these, 42 corresponded to goatlings younger than 15 days and to 6 adult goats between 1 to 5 years. From goatlings younger than 15 days, $42.8 \%$ of the injuries (18 cases) that had a higher occurrence frequency in the liver were: vacuolar degeneration, neutrophilic hepatitis and in some cases, necrotic hepatitis. In $15.7 \%$ of the individuals (6 cases), intralesional intranuclear inclusion bodies were found. At intestinal level, the following injuries were found: lymphocytic enteritis with epithelial desquamation and
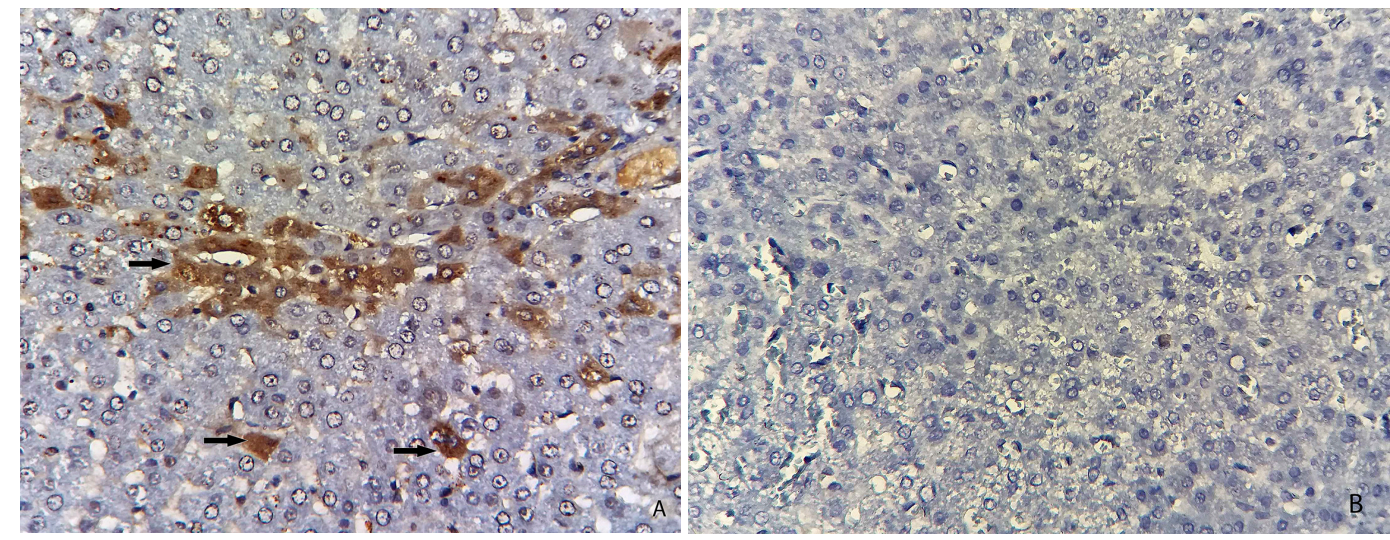

Figure 1. A) Positive control. Immunopositive staining in the hepatocyte cytoplasm of the liver sections of a Syrian golden hamster inoculated with CpHV-1 (arrow). B) Negative control. Liver sections of a clinically healthy Syrian golden hamster without the CpHV-1 antibodies. 
congestion, mild perivascular infiltration, villous atrophy, and sometimes necrotic enteritis. Regarding the 6 adults, in females the most frequent lesions corresponded to genital lesions such as lymphocytic vaginitis in different degrees and ulcerative vulvovaginitis; whereas adult males showed pustular ulcerative balanoposthitis. Only in 2 cases of adult animals, eosinophilic intranuclear intralesional inclusion bodies were found. The lesions found are summarised in table 1.

Out of 48 cases with lesions suggestive of the disease, 28 (58.3\%) showed positivity to the monoclonal anti gC CpHV-1 antibody. Of these, 24 occurred in goatlings younger than 15 days (50\%) and in 4 adults (8.3\%). Detection of CpHV-1 antigens in the hepatocyte cytoplasm around of liver central vein, lung and renal glomerulus was feasible (figure 2).

The obtained data allowed to separate the groups according to their positivity degree, resulting in 25 cases with mild positivity (ocher color), two with moderate positivity (ocher), and one with strong positivity (dark ocher) (figure 3 ).

According to the obtained results, we can suggest the presence of $\mathrm{CpHV}-1$ in the animals whose samples were used in this study. This is related to the observed lesions in the histological liver sections, such as vacuolar degeneration, necrotic hepatitis and in some cases, to the presence of eosinophilic intranuclear inclusion bodies. Such injuries have been previously described by several authors, particularly in goatlings showing the following: inflammatory and necrotic lesions (sometimes hemorrhagic) distributed in the mucosa of the digestive tract; mucosal ulceration, necrosis and edema, accompanied by inflammation of the submucosa in the cecum and colon. Liver cells are swollen and vacuolated, with the presence of intranuclear inclusion bodies (Candanosa et al 2011, Engels and Ackermann 1996, Roperto et al 2000, Smith

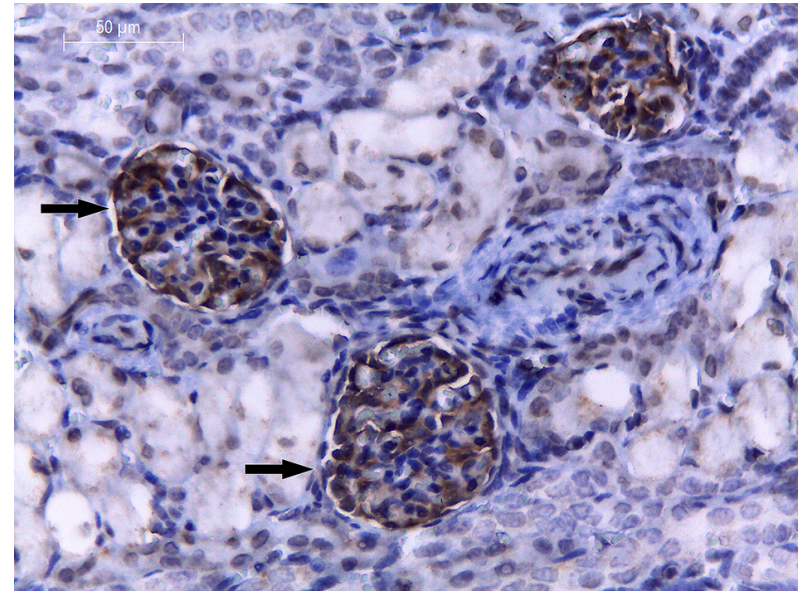

Figure 2. Immunohistochemical localisation of CpHV-1. Strongly immunopositive staining is located in the renal glomerulus (arrow).

1997, Smith and Sherman 2009, Tarigan et al 1987, Thiry et al 2008).

In this study, the majority of IHQ positive cases corresponded to goatlings between 0 and 15 days old. This is consistent with previous reports, since CpHV-1 affects young animals aged one to two weeks old, in which the infection is widespread. In the present study we did not observed all the injuries previously reported by some authors, such as conjunctivitis, serous to purulent nasal mucus, nasal septum ulcers and erosions in the buccal cavity; and sometimes, non-purulent interstitial pneumonia can also be present. Four days after infection, ulcerative lesions may occur in the skin and hooves (Smith and Sherman 2009). The clinical signs of the disease are: progressive weakness, fever, abdominal pain, cyanosis, and rapid heartbeat. Also there is an emission of watery, yellow stools, streaked with blood, but no diarrhea (Mettler et al 1979). Death occurs within the first 5 days, preceded by a comatose state. Some

Table 1. Lesions suggestive of CpHV-1 in a goat herd in Mexico.

\begin{tabular}{|c|c|c|c|c|c|}
\hline \multirow{2}{*}{$\begin{array}{l}\text { Number of } \\
\text { animals }\end{array}$} & \multirow{2}{*}{ Sex } & \multirow{2}{*}{ Age } & \multicolumn{3}{|c|}{ Lesions } \\
\hline & & & Liver & Intestine & Reproductive organ \\
\hline 42 & 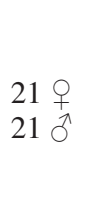 & $<15$ days & $\begin{array}{l}\text { Vacuolar degeneration } \\
\text { Neutrophilic hepatitis } \\
\text { Some intranuclear and } \\
\text { intralesional inclusion bodies }\end{array}$ & $\begin{array}{c}\text { Lymphocytic enteritis } \\
\text { with epithelial } \\
\text { desquamation } \\
\text { Villous atrophy } \\
\text { Some cases with } \\
\text { necrotic enteritis }\end{array}$ & N/A \\
\hline 6 & $\begin{array}{l}3 \text { q } \\
3 \hat{\sigma}\end{array}$ & $1-5$ years & N/A & N/A & $\begin{array}{c}\text { Lymphocytic vaginitis, } \\
\text { vulvovaginitis with mucosal erosion } \\
\text { Intranuclear and intralesional } \\
\text { inclusion bodies } \\
\text { Ulcerative and pustular } \\
\text { balanoposthitis } \\
\text { Intranuclear and intralesional } \\
\text { inclusion bodies }\end{array}$ \\
\hline
\end{tabular}

q Females, $\widehat{\partial}$ Males. 


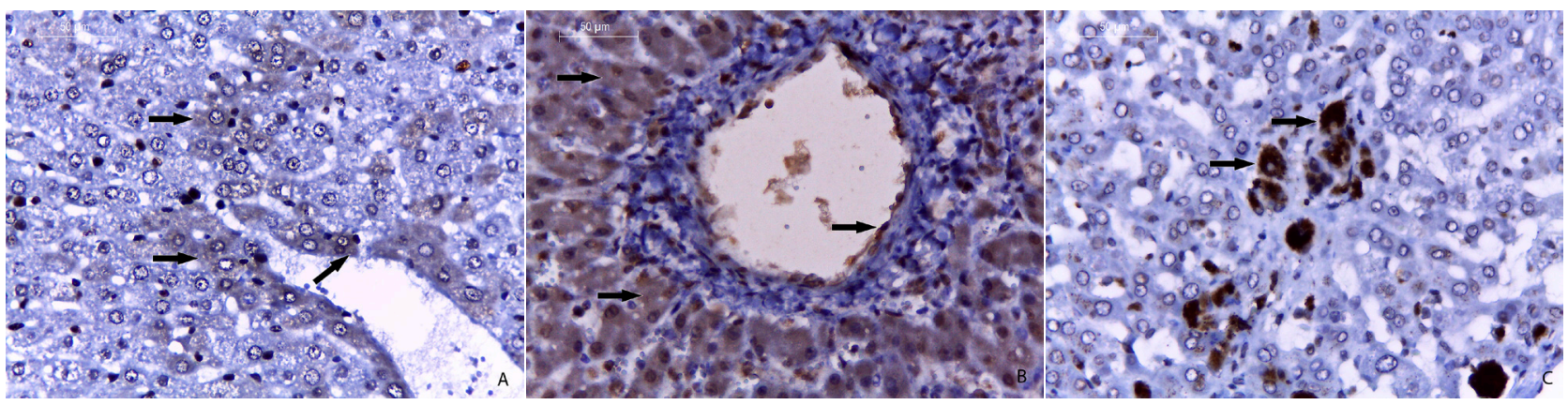

Figure 3. Immunohistochemical localisation of CpHV-1. Immunopositive staining is located in the hepatocyte cytoplasm. A) Mild (arrow); B) Moderate (arrow); C) Strongly (arrow).

goatlings survive or die after two months in a weakness state. However, in this study it was not possible to evaluate the clinical signs of the animals, since they were not recorded in the data provided by the owners.

So far, other diagnostic CpHV-1 studies using IHQ have not been found in Mexico. The use of a monoclonal antibody, which is specific for Caprine alphaherpersvirus 1 (Thiry et al 2008), demonstrates the presence of the disease in the country, and rules out the possibility that it corresponds to a bovine herpesvirus. This is relevant for goat production in the country, since the pathologies associated with reproductive problems are particularly important, because they generate productive and reproductive losses. In this sense, epidemiological surveys are needed in order to detect the presence of antibodies in other Mexican goat production centers, and to determine the economic impact.

According to the results obtained in this study, the presence of herpesvirus was confirmed in the herd. This is the first study in Mexico that confirmed through an immunohistochemical technique and using a monoclonal antibody, the presence of $\mathrm{CpHV}-1$ in goat tissues with lesions compatible with the disease.

\section{ACKNOWLEDGEMENTS}

This work was funded by the "Dirección General de Apoyos al Personal Académico" (DGAPA) of the National Autonomous University of Mexico (UNAM), PAPIIT DGAPA-UNAM IN228511-3. The monoclonal antibody was donated by Dr. Etienne Thiry from the Infectious and Parasitic Disease Department of the Virology and Immunology Laboratory, Faculty of Veterinary Medicine, University of Liege in Belgium. We especially thank QFB Celedonio Gómez, for helping us to standardize the immunohistochemistry test.

\section{REFERENCES}

Candanosa-Aranda IE, Sierra-García M, Sánchez-Cervantes A, Salas-Garrido G, Méndez-Bernal A, et al. 2011. Vulvovaginitis y balanopostitis pustular sugerente a herpesvirus caprino-1 en cabras (Querétaro, México). Vet México 42, 233-243.

Engels M, Ackermann M. 1996. Pathogenesis of ruminant herpesvirus infections. Vet microbiol 53, 3-15.

González J, Passantino G, Esnal A, Cuesta N, García Vera JA, et al. 2017. Abortion in goats by Caprine alphaherpesvirus 1 in Spain. Reprod Dom Anim 52, 1093-1096.

Grewal A, Wells R. 1986. Vulvovaginitis of goats due to a herpesvirus. Austr Vet J 63, 79-82.

Horner G, Hunter R, Day A. 1982. An outbreak of vulvovaginitis in goats caused by a caprine herpesvirus. New Zeal Vet J 30, 150-152.

Keuser V, Schynts F, Detry B, Robert B, Vanderplasschen A, et al. 2004. Improved antigenic methods for differential diagnosis of bovine, caprine, and cervine Alphaherpesviruses related to bovine Herpesvirus 1. J Clin Microbiol 42, 1228-1235.

Koptopoulos G, Papanastasopoulou M, Papadopoulos O, Ludwig H. 1988. The epizootiology of caprine herpesvirus (BHV-6) infections in goat populations in Greece. Comp Immunol Microbiol Infect Dis 11, 199-205.

Mettler F, Engels M, Wild P, Bivetti A. 1979. Herpesvirus-infektion bei zicklein in der Schweiz. Schweizer Archiv für Tierheilkunde $121,655-662$.

Piper K, Fitzgerald C, Ficorilli N, Studdert M. 2008. Isolation of caprine herpesvirus 1 from a major outbreak of infectious pustular vulvovaginitis in goats. Aust Vet $J$ 86, 136-138.

Roperto F, Pratelli A, Guarino G, Ambrosio V, Tempesta M, et al. 2000. Natural caprine herpesvirus 1 (CpHV-1) infection in kids. J Comp Path 122, 298-302.

Saito JK, Gribble DH, Berrios PE, Knight H, McKercher DGA. 1974. New herpesvirus isolate from goats: preliminary report. Am J Vet Res 35, 847-848.

Smith K. 1997. Herpesviral abortion in domestic animals. Vet J 153, 253-268.

Smith M, Sherman D. 2009. Goat medicine. $2^{\mathrm{a}}$ ed. Wiley-Blackwell, New Jersey, USA.

Suavet F, Champion J, Bartolini L, Bernou M, Alzieu J, et al. 2016. First description of infection of cCaprine Herpesvirus 1 (CpHV-1) in goats in mainland France. Pathogens 5, 1-13.

Tarigan S, Webb R, Kirkland D. 1987. Caprine herpesvirus from balanoposthitis. Aust Vet J 64, 321-321.

Thiry J, Saegerman C, Chartier C, Mercier P, Keuser V, et al. 2008. Serological evidence of caprine herpesvirus 1 infection in Mediterranean France. Vet Microbiol 128, 261-268. 